\title{
BOUNDS OF NUMERICAL RADIUS OF BOUNDED LINEAR OPERATORS USING $t$-ALUTHGE TRANSFORM
}

\author{
Santanu Bag, Pintu Bhunia and Kallol Paul
}

Abstract. We develop a number of inequalities to obtain bounds for the numerical radius of a bounded linear operator defined on a complex Hilbert space using the properties of $t$-Aluthge transform. We show that the bounds obtained are sharper than the existing bounds.

Mathematics subject classification (2010): 47A12, 15A60, 47A30.

Keywords and phrases: Numerical radius, Aluthge transform, bounded linear operator, operator inequality.

\section{REFERENCES}

[1] A. ABU-OMAR And F. Kittaneh, A numerical radius inequality involving the generalized Aluthge transform, Studia Math. 216(1) (2013) 69-75.

[2] P. Bhunia, S. BAG AND K. PAUl, Numerical radius inequalities and its applications in estimation of zeros of polynomials, Linear Algebra Appl. 573 (2019) 166-177.

[3] F. Chabbabi And M. MbeKhta, New formulas for the spectral radius via $\lambda$-Aluthge transform, Linear Algebra Appl. 515 (2017) 246-254.

[4] H.-L. GAU, AND P.Y. WU, Equality of three numerical radius inequalities, Linear Algebra Appl. 554 (2018) 51-67.

[5] E. Heinz, Beiträge zur Störungstheorie der Spektralzerlegung, Math. Ann. 123 (1951) 415-438.

[6] I.B. Jung, E. Ko AND C. PEARCY, Aluthge transforms of operators, Integral Equations Operator Theory 37 (2000) 437-448.

[7] F. KitTANEH, Numerical radius inequalities for Hilbert spaces operators, Studia Math. 168(1) (2005) 73-80.

[8] F. Kittaneh, Numerical radius inequality and an estimate for the numerical radius of the Frobenius companion matrix, Studia Math. 158(1) (2003) 11-17.

[9] F. Kittaneh, Commutator inequalities associated with the polar decomposition, Proc. Amer. Math. Soc. 130 (2002) 1279-1283.

[10] K. ОкUво, On weakly unitarily invariant norm and the Aluthge transformation, Linear Algebra Appl. 371 (2003) 369-375.

[11] K. PAUL AND S. BAG, On the numerical radius of a matrix and estimation of bounds for zeros of a polynomial, Int. J. Math. Math. Sci. 2012 (2012) Article Id 129132, https://doi.org/10.1155/2012/129132.

[12] T. YAMAZAKI, On upper and lower bounds for the numerical radius and an equality condition, Studia Math. 178(1) (2007) 83-89.

[13] X. Zhou, J. FAng AND S. Wen, A note on the $C$-numerical radius and the $\lambda$-Aluthge transform in finite factors, Ann. Funct. Anal. 9(4) (2018) 463-473. 